\title{
INVESTIGATION OF THE PROCESS OF ELECTROFLOTATION EXTRACTION OF INSOLUBLE COMPOUNDS ALUMINUM (III) IN THE PRESENCE OF MAGNESIUM, CALCIUM, BARIUM AND SURFACTANTS
}

\author{
Zaw Htay THAN, Pyae AUNG, Thu Aung HEIN, Artem Vladimirovich KOLESNIKOV \\ Mendeleev University of Chemical Technology of Russia, Miusskaya pl. 9, Moscow, 125047 Russia, \\ thanzawhtay20191993@gmail.com
}

https://doi.org/10.37904/metal.2020.3599

\begin{abstract}
The results of experimental studies of the extraction of insoluble aluminum (III) compounds from aqueous solutions in the presence of surfactants of various nature and alkaline earth metal ions $\left(\mathrm{Mg}^{2+}, \mathrm{Ca}^{2+}, \mathrm{Ba}^{2+}\right)$ by the electroflotation method are being explained in this study. A comparative analysis of the influence of these components on the efficiency of electroflotation extraction of aluminum (III) hydroxide is carried out. It was found that the presence in the solution of $\mathrm{Mg}^{2+}, \mathrm{Ca}^{2+}, \mathrm{Ba}^{2+}$ at a concentration of $0.5 \mathrm{~g} / \mathrm{l}$ decreases the extraction degree of $\mathrm{Al}(\mathrm{OH})_{3}$ by electroflotation from $92 \%$ for $\mathrm{Mg}^{2+}$ to $31, \mathrm{Ca}^{2+}$ to $23 \%, \mathrm{Ba}^{2+}$ to $28 \%$ during electroflotation $20 \mathrm{~min}$. Introduction to surfactant systems increases the extraction degree of $\mathrm{Al}(\mathrm{OH})_{3} 64 \%$ for $\mathrm{Mg}^{2+}, 93 \%$ for $\mathrm{Ca}^{2+}, 95 \%$ for $\mathrm{Ba}^{2+}$. The high effectiveness of surfactants is associated with adsorption on $\mathrm{Al}(\mathrm{OH})_{3}$ and hydrophobization of the surface precipitation, which leads to an increase in the degree of electroflotation extraction of the dispersed phase.
\end{abstract}

Keywords: Wastewater treatment, hydroxide ions of aluminum, magnesium, calcium, barium

\section{INTRODUCTION}

In view of the widespread and ever-increasing use of aluminum in high-tech industries, the problem of treating wastewater from its hardly soluble compounds is an urgent task. After being used in various technological processes, aluminum has found its application in high-tech alloys [1,2], energy [3,4].

Aluminum salts are widely used as coagulants for the treatment of industrial and municipal wastewater, as well as in water treatment. Separately, it is worth highlighting the use of aluminum electrodes in such a method of water purification as electrocoagulation [5].

During the processing and use of aluminum, wastewater is generated from the washings, which appear after the following operations: degreasing with organic solvents and pickling; pickling sludge removal; chemical polishing / electrochemical polishing and neutralization; formation of oxide films and filling with dye [6].

Electroflotation is an effective and widely studied method for the extraction of finely dispersed colloidal metal hydroxide systems. It has been published in a large number of works in the Russian Federation [7] and abroad [8].

In the practice of wastewater treatment from $\mathrm{Fe}^{3+}, \mathrm{Al}^{3+}, \mathrm{Cr}^{3+}$, etc. ions, sodium hydroxide or sodium carbonate, calcium, magnesium and barium hydroxides are widely used as reagents. Classical reagents - sodium hydroxide, sodium carbonate, calcium hydroxide have been used in wastewater treatment for many years, magnesium hydroxide has been used in the last 3-5 years [8].

Chlorides, hydroxides and barium carbonates are increasingly used in industry to remove sulfate ions, as well as hexavalent chromium ions in wastewater treatment of galvanic plants, in the form of insoluble compounds $\mathrm{BaSO}_{4}$ and $\mathrm{BaCrO}_{4}$. 
When these reagents are introduced to form precipitates of $\mathrm{Fe}, \mathrm{Cu}, \mathrm{Al}, \mathrm{Cr}, \mathrm{Ni}$, and other metal hydroxides at a high concentration in solutions, primarily soluble magnesium and calcium ions are accumulated, which can affect sedimentation, filtration, and flotation processes.

It was previously noted that when the concentration of soluble salts of magnesium and calcium is up to $0.5 \mathrm{~g} / \mathrm{l}$, the process of electroflotation of hydroxides $\mathrm{Cu}, \mathrm{Zn}$, Ni proceeds less efficiently, the degree of cure is reduced by 1.5 - 2 times technical solutions to increase the efficiency of electroflotation is not an offer.

This work presents for the first time the results of an experimental study of the effect of magnesium, calcium, and barium ions on the electroflotation process of treating aluminum (III) hydroxide in the presence of surfactants of various natures. The electroflotation extraction of aluminum (III) hydroxide was selected as a model system, which is implemented in practice in electroflotation, electroflotocoagulation and electrocoagulation is often found in wastewater treatment.

\section{MATERIALS AND RESEARCH METHODS}

The studies were carried out on model solutions containing aluminum (III) ions and magnesium, calcium and barium ions, as well as surfactants of anionic, cationic and nonionic nature. Sodium chloride at a concentration of $1 \mathrm{~g} / \mathrm{l}$ was used as an electrolyte to create a constant ionic strength.

Model wastewater was cleaned by electroflotation using a laboratory setup consisting of a HY 1803D constant current source, a $500 \mathrm{ml}$ non-flow electroflotator with a cross-sectional area of $10 \mathrm{~cm}^{2}$ and a device height of $80 \mathrm{~cm}$ with an insoluble ORTA anode and a $12 \times 18 \mathrm{H} 10 \mathrm{~T}$ stainless steel cathode according to the method described in the literature [7]. The scheme of the laboratory electroflotation plant of periodic action is presented in Figure 1.

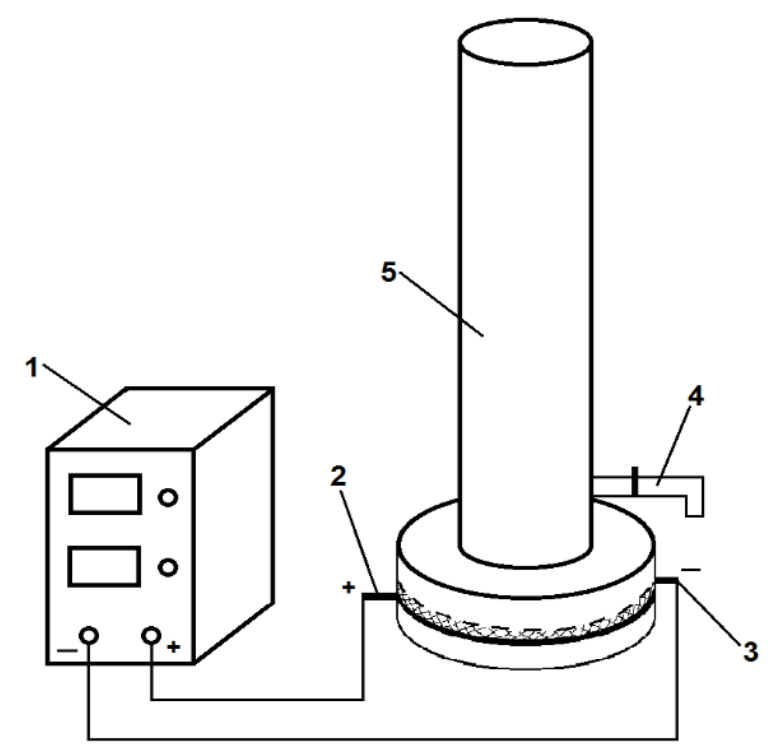

Figure 1 Scheme of a laboratory electroflotation unit of periodic action, 1 - direct current source; 2- anode; 3cathode; 4-valve; 5 - electric flotation column

The efficiency of the electroflotation process was evaluated by the degree of extraction a (\%), which is calculated by the formula:

$\alpha=\frac{\left(C_{i n i}-C_{f i n}\right)}{C_{i n i}} \times 100 \%$

where: $\alpha$ - degree of extraction (\%); Cini-initial concentration of the dispersed phase in the aqueous medium $(\mathrm{mg} / \mathrm{l}) ; \mathrm{C}_{\text {fin }}$ - final concentration of the dispersed phase in the aqueous medium (mg/l). 
The concentration of metal ions was determined by the atomic adsorption method in the D. M. Mendeleev Central research center.

In some cases, after electroflotation purification, an additional filtration of the solution was carried out using anesthetized filters. «Blue ribbon» TY 2642-001-13927158-2003 (pore diameter $\sim 1 \mu \mathrm{m}$ ).

For conducting experiments on electroflotation extraction, dispersed systems of $\mathrm{AlCl}_{3} \times 6 \mathrm{H}_{2} \mathrm{O}$ with a concentration of $100 \mathrm{mg} / \mathrm{l}$ in aqueous solutions, in the presence of surfactants of various natures, metal salts $\left(\mathrm{MgSO}_{4} \cdot 7 \mathrm{H}_{2} \mathrm{O}, \mathrm{CaCl}_{2}, \mathrm{BaCl}_{2} \cdot 2 \mathrm{H}_{2} \mathrm{O}\right.$,) were prepared as a background electrolyte- $\mathrm{NaCl}$ with a concentration of $1 \mathrm{~g} / \mathrm{l}$.

In the experiments, surfactants of various natures were used: cationic surfactant HEV 70 (Didecyldimethylammonium chloride), anionic surfactant (sodium didecylsulfate, NaDDS) and non-ionic surfactant ALM-10 (a mixture of primary hydroxyethylated synthetic higher fatty alcohols of fractions $\mathrm{C}_{12}-\mathrm{C}_{14}$ ) at a concentration of $5 \mathrm{mg} / \mathrm{l}$.

\section{RESULTS AND DISCUSSION}

At the first stage of research, experiments were conducted on the electroflotation extraction of insoluble aluminum (III) hydroxides in the presence of magnesium ions $\left(\mathrm{Mg}^{2+}\right)$ from aqueous $\mathrm{NaCl}$ solutions. The results are presented in Table 1.

Table 1 The effect of $\mathrm{Mg}^{2+}$ ions on the kinetics of electroflotation extraction of aluminum (III) hydroxides

\begin{tabular}{|c|c|c|c|c|c|}
\hline \multirow{2}{*}{$\begin{array}{c}\mathrm{Me}(\mathrm{OH})_{3} \\
\text { (Me-Metals) }\end{array}$} & \multirow{2}{*}{$\begin{array}{l}\text { Electroflotation time } \\
\qquad(\mathrm{min})\end{array}$} & \multicolumn{4}{|c|}{ Degree of extraction $\mathrm{Al}(\mathrm{OH})_{3} \alpha(\%)$} \\
\hline & & $\begin{array}{c}\text { without } \\
\text { surfactant }\end{array}$ & $\begin{array}{l}\text { cationic } \\
\text { surfactant }\end{array}$ & $\begin{array}{l}\text { anionic } \\
\text { surfactant }\end{array}$ & $\begin{array}{l}\text { nonionic } \\
\text { surfactant }\end{array}$ \\
\hline \multirow{3}{*}{$\mathrm{Al}(\mathrm{OH})_{3}$} & 5 & 75 & 80 & 82 & 74 \\
\hline & 10 & 80 & 85 & 90 & 85 \\
\hline & 20 & 92 & 94 & 96 & 90 \\
\hline \multirow{3}{*}{$\mathrm{Al}(\mathrm{OH})_{3}+\mathrm{Mg}^{2+}$} & 5 & 11 & 28 & 40 & 35 \\
\hline & 10 & 27 & 40 & 43 & 52 \\
\hline & 20 & 31 & 54 & 51 & 64 \\
\hline
\end{tabular}

Experiment conditions: $c\left(\mathrm{Al}^{3+}\right)=100 \mathrm{mg} / \mathrm{l} ; c\left(\mathrm{Mg}^{2+}\right)=0.5 \mathrm{~g} / \mathrm{l} ; c($ Surfactant $)=5 \mathrm{mg} / \mathrm{l} ; c(\mathrm{NaCl})=1 \mathrm{~g} / \mathrm{l} ; \mathrm{i}_{\mathrm{v}}=0.4 \mathrm{~A} / \mathrm{l} ;$ $\mathrm{pH}=7$.

It was noted that in the absence of surfactants without the addition of magnesium ions, the electroflotation process is very effective; the degree of extraction of aluminum (III) in 20 minutes reaches $92 \%$. In addition, the presence of various surfactants (cationic, anionic and nonionic types) electroflotation process changes slightly, the degree of extraction reaches $94-96 \%$ after 20 minutes of the electroflotation process. With the introduction of a system of magnesium ions, the degree of extraction decreases after 20 minutes, reaching $31 \%$. Also revealed decrease in the speed of the electroflotation process, as evidenced by the data for the first 5 and 10 minutes of treatment. It was noted earlier that due to the adsorption of $\mathrm{Ca}^{2+}$ and $\mathrm{Mg}^{2+}$ ions on $\mathrm{Cu}, \mathrm{Ni}$, and $\mathrm{Zn}$ hydroxides, the degree of extraction decreases.

At the next stage, the effect of other metals on the electroflotation extraction of insoluble aluminum (III) compounds in the presence of surfactants was studied (Tables 2 and $\mathbf{3}$ ).

It was found that calcium ions negatively affect the electroflotation process, the degree of extraction decreases to $23 \%$, which indicates a stronger effect of $\mathrm{Ca}^{2+}$ ions than $\mathrm{Mg}^{2+}$. When a surfactant is introduced into the system, the electroflotation process proceeds more effectively, which allows achieving the high degree of 
extraction $90 \%$ - 95\%. As already noted, $\mathrm{Ba}^{2+}$ ions are often used to remove $\mathrm{SO}_{4}{ }^{2-}, \mathrm{CrO}_{4}{ }^{-}$anions from galvanic wastewater from another country. $\mathrm{Ba}^{2+}$ ions remain in solutions and can precipitate the flotation and sedimentation processes.

Table 2 The effect of $\mathrm{Ca}^{2+}$ ions on the kinetics of electroflotation extraction of aluminum (III) hydroxides

\begin{tabular}{|c|c|c|c|c|c|}
\hline \multirow{2}{*}{$\begin{array}{c}\text { Me(OH) } \\
\text { (Me-Metals) }\end{array}$} & $\begin{array}{c}\text { Electroflotation time } \\
(\text { min) }\end{array}$ & \multicolumn{4}{|c|}{ Degree of extraction $\mathbf{A l}(\mathbf{O H})_{3} \mathbf{\alpha}(\%)$} \\
\cline { 2 - 5 } & without & $\begin{array}{c}\text { cationic } \\
\text { surfactant }\end{array}$ & $\begin{array}{c}\text { anionic } \\
\text { surfactant }\end{array}$ & $\begin{array}{c}\text { nonionic } \\
\text { surfactant }\end{array}$ \\
\hline \multirow{3}{*}{$\mathrm{Al}(\mathrm{OH})_{3}$} & 5 & 75 & 80 & 82 & 74 \\
\cline { 2 - 6 } & 10 & 80 & 85 & 90 & 85 \\
\cline { 2 - 6 } & 20 & 92 & 94 & 96 & 90 \\
\hline \multirow{3}{*}{$\mathrm{Al}(\mathrm{OH})_{3}+\mathrm{Ca}^{2+}$} & 5 & 17 & 65 & 80 & 72 \\
\cline { 2 - 6 } & 10 & 18 & 80 & 82 & 80 \\
\cline { 2 - 6 } & 20 & 23 & 92 & 92 & 93 \\
\hline
\end{tabular}

Experiment conditions: $c\left(\mathrm{Al}^{3+}\right)=100 \mathrm{mg} / \mathrm{l} ; c\left(\mathrm{Ca}^{2+}\right)=0.5 \mathrm{~g} / \mathrm{l} ; \mathrm{c}($ Surfactant $)=5 \mathrm{mg} / \mathrm{l} ; c(\mathrm{NaCl})=1 \mathrm{~g} / \mathrm{l} ; \mathrm{i}_{\mathrm{v}}=0.4 \mathrm{~A} / \mathrm{l}$; $\mathrm{pH}=7$.

Table 3 shown the data on the effect of $\mathrm{Ba}^{2+}$ ions on the kinetics of the electroflotation process for the extraction of $\mathrm{Al}(\mathrm{OH})_{3}$ in the presence of surfactants.

Table 3 The effect of $\mathrm{Ba}^{2+}$ ions on the kinetics of electroflotation extraction of aluminum (III) hydroxides

\begin{tabular}{|c|c|c|c|c|c|}
\hline \multirow{2}{*}{$\begin{array}{c}\text { Me(OH) } \\
(\mathbf{M e}-\text { Metals) }\end{array}$} & $\begin{array}{c}\text { Electroflotation time } \\
(\mathrm{min})\end{array}$ & $\begin{array}{c}\text { Dithout } \\
\text { surfactant }\end{array}$ & $\begin{array}{c}\text { cationic } \\
\text { surfactant }\end{array}$ & $\begin{array}{c}\text { anionic } \\
\text { surfactant }\end{array}$ & $\begin{array}{c}\text { nonionic } \\
\text { surfactant }\end{array}$ \\
\cline { 2 - 6 } & 5 & 75 & 80 & 82 & 74 \\
\hline \multirow{3}{*}{$\mathrm{Al}(\mathrm{OH})_{3}$} & 10 & 80 & 85 & 90 & 85 \\
\cline { 2 - 6 } & 20 & 92 & 94 & 96 & 90 \\
\hline \multirow{3}{*}{$\mathrm{Al}(\mathrm{OH})_{3}+\mathrm{Ba}^{2+}$} & 5 & 18 & 80 & 90 & 81 \\
\cline { 2 - 6 } & 10 & 20 & 84 & 92 & 85 \\
\cline { 2 - 6 } & 20 & 28 & 90 & 93 & 96 \\
\hline
\end{tabular}

Experiment conditions: $\mathrm{c}\left(\mathrm{Al}^{3+}\right)=100 \mathrm{mg} / \mathrm{l} ; \mathrm{c}\left(\mathrm{Ba}^{2+}\right)=0.5 \mathrm{~g} / \mathrm{l} ; \mathrm{c}($ surfactant $)=5 \mathrm{mg} / \mathrm{l} ; \mathrm{c}(\mathrm{NaCl})=1 \mathrm{~g} / \mathrm{l} ; \mathrm{i} \mathrm{v}=0.4 \mathrm{~A} / \mathrm{l}$; $\mathrm{pH}=7$.

Analyzing the data of Table 3, it was found that the rate of the $\mathrm{Al}(\mathrm{OH})_{3}$ extraction process decreases in the presence of $\mathrm{Ba}^{2+}$ ions, and the process is more inhibited with an increase in their concentration. The introduction of barium ions negatively affects the process of electroflotation in the absence of surfactants; the degree of extraction does not exceed $28 \%$ in 20 minutes of electroflotation. In the case of the presence of cationic surfactantandnonionic surfactant in the system, the electroflotation extraction of aluminum (III) hydroxide is sharply intensified when barium ions are introduced, the degree of extraction after 20 minutes of treatment reaches $90-96 \%$. At the same time, the influence of barium ions together with anionic surfactants has a positive effect on the electroflotation extraction; the degree of extraction exceeds $90 \%$ already in the first 5 minutes of treatment. The effect of anionic surfactants on the kinetics of electroflotation extraction of aluminum (III) hydroxide in the presence of calcium, magnesium and barium ions is shown in Figure 2.

In a system without metal ions and surfactant additives, the extraction of aluminum (III) hydroxides proceeds efficiently regardless of the nature of the surfactant. With the introduction of magnesium ions, the process is 
substantially suppressed. These effects are associated with $\mathrm{Mg}^{2+}$ adsorption on $\mathrm{Al}(\mathrm{OH})_{3}$ precipitates, which leads to a change in the electro kinetic $\zeta$ - potential of the particles and to an increase in the positive charge. The maximum flotation activity is possessed by uncharged particles of the $\zeta$ - potential, which are closer to zero.

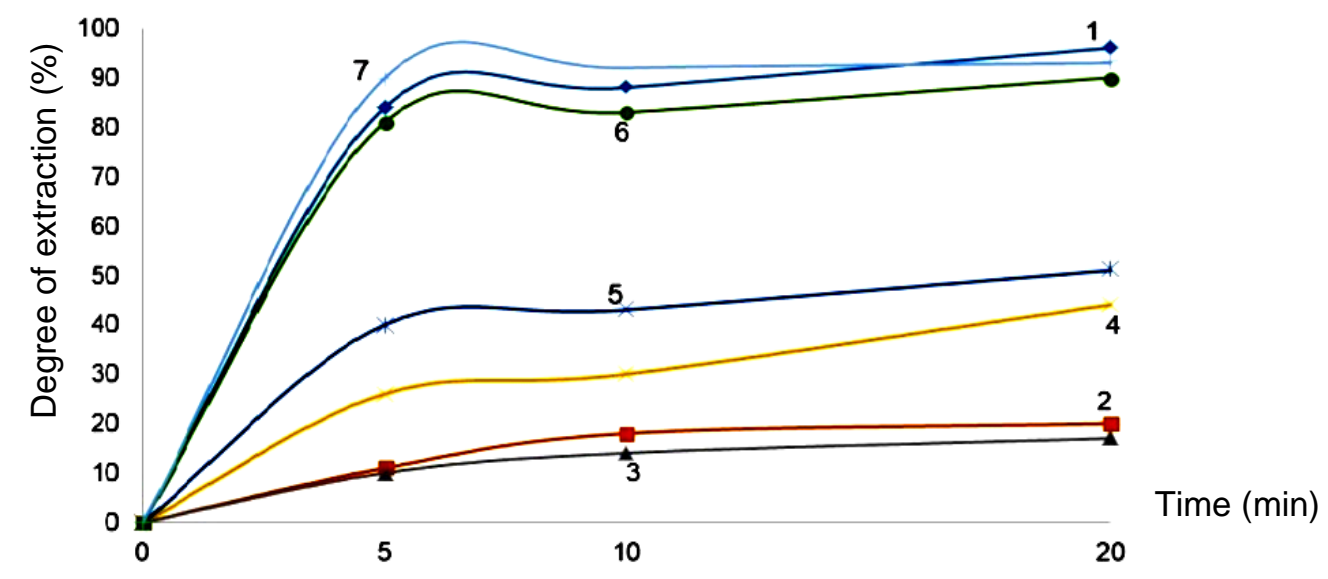

Figure 2 The effect of anionic surfactants on the kinetics of electroflotation extraction of insoluble $\mathrm{Al}^{3+}$ compounds in the presence of ions $\mathrm{Mg}^{2+}, \mathrm{Ca}^{2+}, \mathrm{Ba}^{2+}$

Note: experimental conditions: $\mathrm{c}\left(\mathrm{Al}{ }^{3+}\right)=100 \mathrm{mg} / \mathrm{l} ; \mathrm{c}(\mathrm{NaCl})=1 \mathrm{~g} / \mathrm{l} ; \mathrm{c}\left(\mathrm{Mg}^{2+}\right)=0.5 \mathrm{~g} / \mathrm{l} ; \mathrm{c}\left(\mathrm{Ca}^{2+}\right)=0.5 \mathrm{~g} / \mathrm{l} ; \mathrm{c}\left(\mathrm{Ba}^{2+}\right)=$ $0.5 \mathrm{~g} / \mathrm{l} ; \mathrm{pH}=7 ; \mathrm{c}$ (surfactant) $=5 \mathrm{mg} / \mathrm{l} ; \mathrm{i}_{\mathrm{v}}=0.4 \mathrm{~A} / \mathrm{l}, 1-\mathrm{Al}(\mathrm{OH})_{3}+$ anionic surfactants; $2-\mathrm{Al}(\mathrm{OH})_{3}+\mathrm{Mg}^{2+} ; 3-$ $\mathrm{Al}(\mathrm{OH})_{3}+\mathrm{Ca}^{2+} ; 4-\mathrm{Al}(\mathrm{OH})_{3}+\mathrm{Ba}^{2+} ; 5-\mathrm{Al}(\mathrm{OH})_{3}+\mathrm{Mg}^{2+}+$ anionic surfactants; $6-\mathrm{Al}(\mathrm{OH})_{3}+\mathrm{Ca}^{2+}+$ anionic surfactants; $7-\mathrm{Al}(\mathrm{OH})_{3}+\mathrm{Ba}^{2+}+$ anionic surfactants;

According to the results of experimental studies, it was found that calcium and barium ions with anionic surfactants positively affect the kinetics of the electroflotation extraction of insoluble aluminum (III) compounds. The comparative effect of the nature of surfactants on the efficiency of electroflotation extraction of aluminum (III) hydroxides is shown in Figure 3.

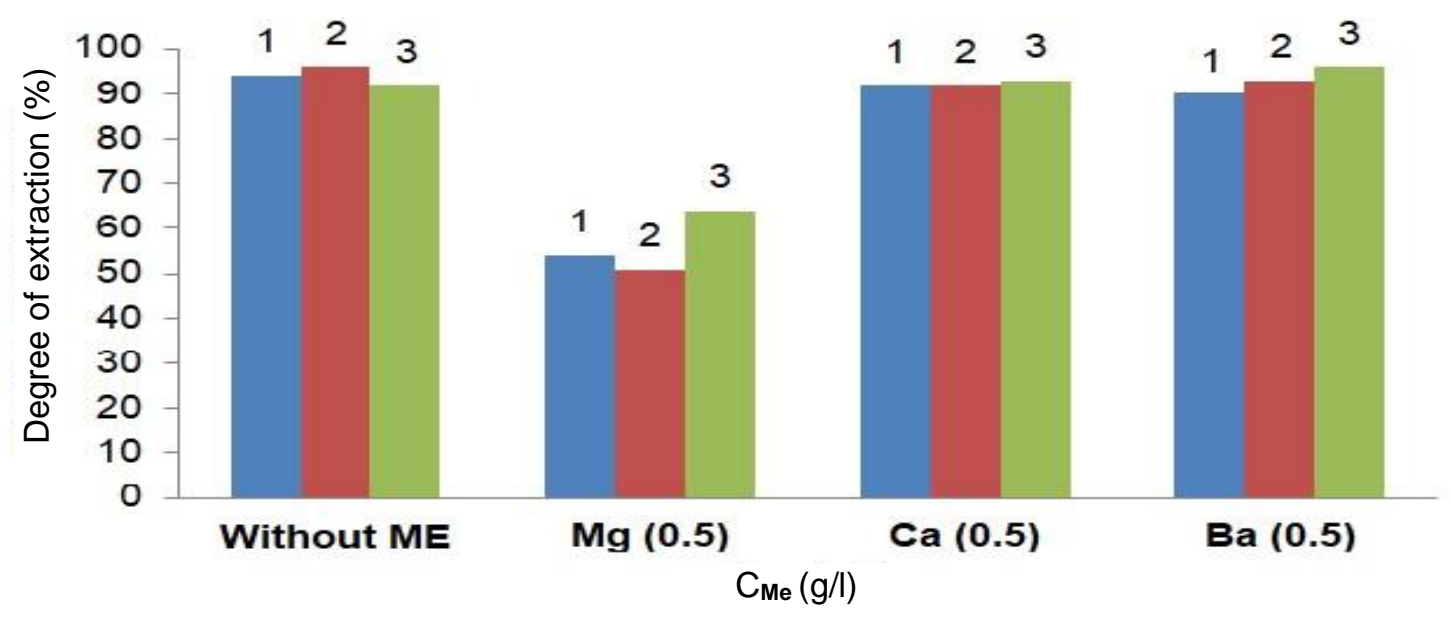

Figure 3 The effect of magnesium, calcium and barium ions on the efficiency of electroflotation extraction of aluminum (III) hydroxides in the presence of various surfactants; $c\left(\mathrm{Al}^{3+}\right)=100 \mathrm{mg} / \mathrm{l} ; \mathrm{c}\left(\mathrm{Mg}^{2+}\right)=0.5 \mathrm{~g} / \mathrm{l} ; \mathrm{c}\left(\mathrm{Ca}^{2+}\right)$ $=0.5 \mathrm{~g} / \mathrm{l} ; \mathrm{c}\left(\mathrm{Ba}^{2+}\right)=0.5 \mathrm{~g} / \mathrm{l} ; \mathrm{c}(\mathrm{NaCl})=1 \mathrm{~g} / \mathrm{l} ; \mathrm{c}($ surfactant $)=5 \mathrm{mg} / \mathrm{l} ; \mathrm{i}_{\mathrm{v}}=0.4 \mathrm{~A} / \mathrm{l} ;$ time $=20 \mathrm{~min}$;

1 - cationic surfactants; 2 - anionic surfactants; 3 - nonionic surfactants 


\section{CONCLUSION}

In the course of experimental studies, it was found that the adsorption of magnesium, calcium and barium ions reduces the degree of electroflotation extraction of aluminum (III) hydroxide from $92 \%$ to $31 \%$ in the presence of magnesium ions, to $21 \%$ in the presence of calcium ions and to $23 \%$ in the presence of barium ions. The studied cationic surfactant and non-ionic surfactant have a positive effect on the electroflotation extraction of insoluble aluminum (III) compounds in the presence of magnesium ions, the degree of extraction increases from $39 \%$ to $64 \%$ in the presence of non-ionic surfactant. The introduction of anionic surfactant has a positive effect on the electroflotation process: the degree of extraction increases to $51 \%$ in the presence of magnesium ions, to $92 \%$ in the presence of calcium ions and to $93 \%$ in the presence of barium ions, and in some cases the process is accelerated. This effect is explained by the adsorption of anionic surfactants on the surface of the dispersed phase of aluminum (III) hydroxide, which gives it more hydrophobic properties and increases the efficiency of the electroflotation process.

\section{ACKNOWLEDGEMENTS}

I would like to express my very great appreciation to Doctor of technical Sciences, Professor Kolesnikov V.A., my research supervisors, for his valuable and constructive suggestions during the planning and development of this research work. I would also like to thank Mr. Kolesnikov A.V (Candidate of Technical Sciences, senior researcher of Technopark "Ecochemical 2000+" Mendeleev, and Ph.D., doctoral student Mr. Hein Thu Aung for their advice and assistance in keeping my progress. My grateful thanks are also extended to Ph.D. student Mr. Aung Pyae for his help in doing experiment and analysis. My special thanks are extended to the administrator and organization of the Conference METAL 2020 for invitation. The work was carried out with financial support DI. Mendeleev (project No. Z-2020-004).

\section{REFERENCES}

[1] GANIEV, I.N., ALIEV, D.N., NARZULLOEV, Z.F. The effect of nickel additives on the anode behavior of zincaluminum alloys Zn5Al, Zn55Al in a NaCl electrolyte. Journal of Applied Chemistry. 2019, vol. 92, no. 11, pp. 1420-1426.

[2] YATSENKO, S.P., PASECHNIK, L.A., JUMPS, V.M. Scandium: obtaining and application // news of materials science. Science and Technology. 2015, vol. 15, no. 3, pp. $32-37$.

[3] KISELEVA, E.A, ZHUK, A.Z., KLEIMENOV, B.V., UDALTSOV,V.G. Development and research of gas diffusion cathodes as a part of cylindrical elements of an air-aluminum electrochemical generator. Journal of Applied Chemistry. 2018, vol. 91, no. 1, pp. 65-69.

[4] ISUPOV, V.P., BULINA, N.V., BORODULINA,I.A. The effect of water vapor pressure on the phase composition of lithium monoaluminates formed during the interaction of aluminum hydroxide and lithium carbonate. Journal of Applied Chemistry. 2017, vol. 90, no. 8, pp. 986-991.

[5] KOLESNIKOV, V.A., ILYIN, V.I., BRODSKY, V.A., KOLESNIKOV, A.V. Electroflotation in the processes of water purification and extraction of valuable components from liquid industrial waste. Theoretical Foundations of Chemical Technology. 2017, vol. 51, no. 4, pp. 361-375.

[6] SKOPINTSEV, V.D. Oxidation of aluminum and its alloys. M. D. Mendeleev University of Chemical Technology of Russia, 2015.

[7] KSENTINI, I., KOTTI, M., BEN MANSOUR,L. Effect of liquid phase physicochemical characteristics on hydrodynamics of an electroflotation column. Desalination and Water Treatment. 2014, vol. 52, no. 16-18, pp. 3347.

[8] MALKOVA, Yu.O., BRODSKY, V.A., KOLESNIKOV, V.A. Increasing the efficiency of electroflotation extraction of $\mathrm{Pb}$ (II) ions from aqueous solutions in the presence of $\mathrm{Al}(\mathrm{III})$ and $\mathrm{Fe}(\mathrm{III})$ ions as coagulants. Vestn. Mosk. UN-TA. ser. 2. Chemistry. 2020, vol. 61, no. 2, pp. 166-173. 